\section{The Wartime Social Survey}

ONE of the most recent developments in State research in the field of sociology is the Wartime Social Survey. After an initial period of growing pains, this Survey is now emerging as a valuable machine for conducting any type of inquiry capable of investigation by the method of interviewing samples of the population. Two Government Departments, the Ministries of Information and Food, required a market research machine for investigating the effects of their advertising. When the Wartime Social Survey was set up to meet this need, it became apparent that there were problems facing other Government Departments which could only be solved by the method of interviewing samples of the population, and to meet this need the Survey was extended. It now carries out investigations for not only the Ministries of Information and Food, but also for the Board of Trade, the Ministries of Health, Home Security, Works and Buildings, Supply and the War Office.

With the exception of its superintending research officer, none of its staff are Civil servants. This is one of an elaborate series of precautions adopted to make sure that the names of the persons interviewed are not available to the Civil Service. The headquarters staff consists of eight scientific workers, a number of coding tabulators, administrative officers, etc., while the interviewing staff consists of about fifty field-workers. So that this level of scientific work shall be as high as possible, a small panel of scientific consultants has been set up. They are Prof. A. M. Carr-Saunders, Prof. L. T. Hogben, Mr. B. Seebohm-Rowntree, Mr. A. D. K. Owen, Dr. Bradford Hill, and Dr. Aubrey J. Lewis. Every report produced is submitted in interim form to the consultants for critical comment before the final draft is prepared. Further, technical problems in the phrasing of questions, the selection of samples, etc., are submitted, particularly when any difference of opinion arises between a requesting Department and the scientific staff of the Survey. Owing to the speed at which war-time investigations have to be carried out, more detailed consultation is impossible, but the present system has shown that the needs of Government Departments for social survey investigation can be met by a Government-controlled machine without loss of scientific impartiality. Among studies recently undertaken are: the feeding of employed adolescents.; the methods of heating and cooking in working-class households; salvage habits; clothes-rationing problems; food-rationing problems; and a study of female foundation garments. It will be noted, of course, that this useful Survey is dealing with problems arising out of the War.

\section{Nazism and Science}

IN a recent Thinker's Forum pamphlet entitled "The Nazi Attack on International Science" (London: C. A. Watts and Co., Ltd., 6d.), Dr. Joseph Needham presents a brief but telling analysis of the nature of Nazism, and describes some of the effects it has produced in science and learning both inside Germany and outside. Society is now passing through an era of change from individualistic capitalistic economics to some form of collectivism, and just as the earlier change from a feudal aristocracy to capitalist democracy was marked by violent upheavals such as the Thirty Years' War and the French Revolution, so Dr. Needham believes that Nazism and Fascism are by-products of the present phase of the evolution of society. The necessary conditions are two powerful groups between which there are relations of mutual fear ; and the racketeer, in this case the Nazi, plays off one against the other. The Nazis have played this part successfully with the German people and also with other nations. Having attained power, the Nazis had to have "a nation of tools". This they achieved by the doctrines of anti-intellectualism, racialism, restriction of science to matters of military value, and the principle of the 'leader'. Incidentally, Dr. Needham points out that the war between China and Japan has its origin in a similar racialnational spirit which has arisen in the latter country.

Turning to biological fallacies exploited by the Nazis, Dr. Needham refers particularly to their misuse of the doctrine of the struggle for existence; they overlook the distinction between inter- and intra-specific competition, forgetting that the latter has led to the development of unwieldy size, exaggerated fertility and other characteristics which in the past have brought about the extinction of the species concerned. They also make play with the analogy between the social organism and the animal body with its various organs or members. But associations of organisms capable of rational thought cannot be regarded as associations of living cells having only the primitive characters of life. It is a fundamental mistake "to suppose that higher levels of organization can be explained and handled in terms of lower levels". Dr. Needham recapitulates the facts already known about the repression of learning in Germany and the occupied countries, the dismissals of staff and their replacement, if at all, by political figures. One example of the effect of repression on scientific publications quoted by Dr. Needham is worth mention. Three scientific journals in his own field of work were, even before the War, one fifth or less of their former size ; one of these, the Biochemische Zeitschrift, decreased from 13 volumes in 1927 to 5 in 1938 and 2 in 1939 , although the number of non-German contributors remained roughly the same. Science in Nazi Germany is valued solely in its relation to the needs of war.

\section{British Electrical and Allied Industries Research Association}

The twenty-first annual report (Ref. E.R.A./T320) of the British Electrical and Allied Industries Research Association summarizes the work which has been carried out during the year ended September 30, 1941 , and lists by titles the various research reports which have been issued during the period. The work is reviewed in seventeen major classifications among which are the highly important ones of dielectrics, cables and overhead lines, electric control apparatus, steam-power plant and condensers, magnetic materials, transformers, surge phenomena and rural electrification. Emphasis is laid upon the work which is still being carried out on circuit making and breaking, surge phenomena, and the properties of insulation, and attention is directed to the consideration now being given, for example, to the storage of electrical energy, the mechanical strength of transformer windings, and the quality improvement of electrical sheet steel. Practical circuit breaker design has been influenced considerably by the Association's investigations. In the 
insulating materials field, speeial account is being taken of the latest developments in plastics.

A new section with appropriate sub-committees has been set up to deal with problems of transformer engineering arising especially from war-time and post-war requirements. An exhaustive account has been published of seven years investigation for the Central Electricity Board on surge phenomena, and work has been carried out at the National Physical Laboratory on the surge properties of insulating materials and the surge resistance of tower footings. Researches on conductors, earthing, continuity and on electric control apparatus continue, and the hard gas eircuit breaker is receiving special attention. The work of the Association on the application of electricity to agriculture and horticulture continues and is beginning to receive wider recognition in those circles.

The report discloses that the work of the Association is now carried on by no less than 109 technical sections, sub-committees and panels, comprised of experts engaged in industry and in universities and other training institutions. Eighty-three technical reports, relating to a wide variety of subjects, have been issued by the Association during the year, and thirty others were in an advanced stage of preparation at the end of the year. The Association has been recognized as an essential undertaking and a closer liaison has been developed during the year with the Ministry of Supply and, to a lesser degree, with the Fighting Services. The activities of the Information Bureau and Library have been increased by wartime requirements, and work on a complete analytical index to reports of the Association has been carried on during the year. The report is an encouraging survey of the researches which are being undertaken for the electrical industry to meet the needs, not only of war-time requirements, but also of the post-war reconstruction period. It is rightly considered that particular importance should be attached to reconstruction problems, which should receive adequate and timely attention from the point of view of research as new ideas, findings and methods must be absorbed by industry long before research results are needed in commereial enterprises.

\section{Agricultural Meteorology in India}

THe annual report of the Agricultural Meteorology Section, India Meteorological Department, for the year 1939-40 covers the last year during which the section was being financed by the Imperial Council of Agricultural Research, the Government of India having taken over the Section from April 1, 1940. The report describes a number of investigations, most of them concerned with the micro-climatology of crops, that is, with the climates experienced within growing crops, as distinct from the more artificial climate of the ordinary meteorological instrument enclosure which is of greater interest for comparisons between the climates of different countries. A number of new instruments have been developed, including several forms of portable but accurate galvanometer for use with thermocouples of copper and constantan for the measurement of temperature in microclimatology. The recently completed 35 -ft. tower at the Central Agricultural Meteorological Observatory at Poona has been found very useful for mounting thermographs, hygrometers and anemometers, for studies of the variations of temperature, humidity and wind with height, which are important in the control of the vertical exchange of heat and moisture between the soil and the overlying air. At Poona, insolation even in January is found to be so strong that the convective layer, with temperature decreasing with height, does not normally disappear during the night, and is generally still to be observed as a layer one or two feet thick at 6 a.m., when temperature in the lower layers is near its minimum. At that time it is generally coldest at a height of one or two feet, with temperature increasing upwards from that level for several hundred feet, the rise amounting already to about $3^{\circ} \mathrm{C}$. on reaching the top of the 35-ft. tower. By April the greater insolation is more than counteracted in its tendency to maintain the convective layer by the effect of a higher average nocturnal wind speed, the net result being that the layer has almost disappeared by 6 a.m. The report includes a number of other studies relating to micro-climatology, among which is a table showing the average wind speed in the afternoon at various heights up to $8 \mathrm{ft}$. in eight different crops, expressed as a percentage of the wind at the same height above open ground. Up to $2 \mathrm{ft}$., wheat and sugar cane show the highest degree of sheltering, tobacco and suran the least.

\section{Nobel Laureates in the United States}

THE philanthropy of Alfred Nobel, the Swedish industrialist, is usually commemorated on December 10 in Stockholm or Oslo with the announcement of the new Nobel Prize winners. In its place a dinner was held in the United States on December 11 at which eleven Nobel laureates were guests of honour. The celebration marked the fortieth anniversary of the first awards. Nobel laureates who were present at the dinner included Dr. Viktor F. Hess, Dr. C. J. Davisson, Prof. Enrico Fermi, Prof. Otto Meyerhof, Dr. Karl Landsteiner, Dr. Irving Langmuir, Prof. H. C. Urey and Prof. Peter J. W. Debye. Dr. Vilhjalmur Stefansson presided.

\section{Medical Research Council: Radiotherapeutic Research Unit}

The Medical Research Council announces that its Radiotherapeutic Research Unit (formerly Radium Beam Therapy Research) has now resumed clinical work in new quarters which have been provided by the London County Council at Hammersmith Hospital. For the present, this work will be confined to the treatment, by radium beam therapy or X-rays, of cases of carcinoma affecting the buccal cavity, tongue, pharynx and larynx. The director, Dr. Constance A. P. Wood, would be glad to have suitable cases referred to her: these should be patients who have had no previous treatment, either surgical or radiological, and preferably not in a very advanced stage of the disease. The physical work under the charge of Mr. L. G. Grimmett, which has meanwhile been continued in temporary quarters at the Imperial College of Science and Technology, has also been transferred to Hammersmith Hospital.

\section{American Chemical Society: New President}

Dr. Per K. Frolich, director of the Chemical Division of the Esso Laboratories of the Standard Oil Development Company at Elizabeth, N.J., known for his work in the development of synthetic rubber, has been elected president of the American Chemical Society for 1943. Dr. Frolich took 